\title{
Fischer-Tropsch synthesis: product distribution, operating conditions, iron catalyst deactivation and catalyst speciation
}

\author{
Joshua Gorimbo ${ }^{1} \cdot$ Adolph Muleja $^{2} \odot \cdot$ Xinying Liu $^{1} \cdot$ Diane Hildebrandt $^{1}$
}

Received: 28 February 2018 / Accepted: 14 November 2018 / Published online: 26 November 2018

(c) The Author(s) 2018

\begin{abstract}
Laboratory experiments conducted for long time on stream (TOS: 14,350 h) provide information on Fischer-Tropsch synthesis (FTS) that is representative of time scales of industrial operations. Operation conditions that deliver desirable conversion and product distribution were investigated. Low gas hourly space velocity (GHSV) gave the highest conversion of 20.97\% with the highest $\mathrm{C}_{5+}$ selectivity achieved was $59.77 \%$, which was obtained at the highest GHSV level. A one-way ANOVA, followed by a post-hoc Bonferroni correction test, indicated a significant difference in response to GHSV with $\mathrm{P}(\mathrm{T}<=\mathrm{t})$ two-tail values ranging from $1.5 \times 10^{-4}$ to $2.7 \times 10^{-35}$. The optimum condition for paraffin production is high pressure and low GHSV: in our experiments, this corresponded to 20.85 bar (abs): $648 \mathrm{~h}^{-1}$. Conversely, olefins production is favored low pressure and low GHSV [1.85 bar (abs): $648 \mathrm{~h}^{-1}$ ]. $\mathrm{C}_{5+}$ production was favored at high GHSV $\left(2592 \mathrm{~h}^{-1}\right)$ and was very sensitive to GHSV, as the sensitivity to $\mathrm{C}_{5+}$ products dropped sharply when the GHSV decreased to low values (from 1296 to $648 \mathrm{~h}^{-1}$ ); furthermore, the selectivity to $\mathrm{C}_{5+}$ was found to be independent of pressure. The pressure effect on selectivity is complex and selectivity toward overall gaseous (paraffin + olefin) hydrocarbons and $\mathrm{C}_{5+}$ does not seem to be significantly affected by variations in pressure. Long TOS FTS runs are possible ca. 14,500 h though product distribution trends tend to be changed. The catalyst survived long runs, though the selectivity to FTS became comparatively less favored than WGS with increasing TOS. Our findings may have useful implication for the design of a mobile small-scale biomass/waste to liquid process that would last for period similar to that of an industrial plant.
\end{abstract}

Keywords Fischer-Tropsch synthesis · Iron catalyst · Reduction · Time on stream · Product distribution · Catalyst activity

\section{Introduction}

Fisher Tropsch synthesis (FTS) is an established technology that produces synthetic petroleum fuels (synfuels), chemical feedstock and pipeline gas. The most commonly used active metals catalyst in FTS are iron and cobalt, as these provide technical and economic advantages. Synthesis gas (syngas), which is a mixture of carbon monoxide and hydrogen (the stoichiometric ratio required is around 1:2), is used for FTS.

Joshua Gorimbo

joshuagorimbo@gmail.com

1 Institute for the Development of Energy for African Sustainability (IDEAS) Research Unit, University of South Africa (UNISA), Florida Science Campus, Private Bag X6, Johannesburg 1710, South Africa

2 College of Science, Engineering and Technology (CSET), University of South Africa (UNISA), Florida Science Campus, Private Bag X6, Johannesburg 1710, South Africa
The composition of the feed syngas is important as it affects the activity and selectivity of catalyst and even the presence of inert gases such as nitrogen in the feed can affect the reaction. Muleja et al. [1] reported that when nitrogen is co-fed to fixed bed FT reactor loaded with a cobalt catalyst, the selectivity to $\mathrm{C}_{5+}$ (particular $\mathrm{C}_{5}-\mathrm{C}_{19}$ ) fraction is enhanced. Syngas can also be used for the reduction/activation of FT catalyst [2], but the composition of the syngas can influence the selectivity and activity of the catalyst. Chun et al. [3] conducted experiments on a highly selective iron-based FT catalysts activated by $\mathrm{CO}_{2}$-containing syngas. They found that the activation with this gas suppressed the production of undesired products, namely $\mathrm{CH}_{4}$ and $\mathrm{C}_{2}-\mathrm{C}_{4}$ hydrocarbons; and facilitated the production of valuable products the $\mathrm{C}_{5+}$ hydrocarbons. FTS is a chemical process that depends on operational conditions, including time on stream (TOS), space velocity (SV), pressure and temperature. Researchers [2-5] have reported on these factors, and how they influence the product distribution of hydrocarbons 
during FTS. One of the drawbacks to this research is that the experiments were conducted under conditions that do not reflect the real pilot or industrial plant operations, as the laboratory data are usually reported for relatively short TOS.

The literature is rich with information on the effect of process parameters on FTS at short TOS, for example, Bukur, ran up to TOS $140 \mathrm{~h}$ [4], Todic et al. [5] ran longer for TOS of up to $654 \mathrm{~h}$; therefore, the findings may not hold for extended reaction times that are used industrially. The phenomenon of catalyst speciation (phase changes of the active catalyst to an inactive phase) or simply deactivation, which is a function of TOS, has a major influence on activity and product distribution. Hence, an understanding of the catalyst performance at long TOS is important.

The relationship between SV, pressure $P$, temperature $T$ and contact time $\theta$ is as shown by the following equation:

$\theta=\frac{1}{\mathrm{SV}} \cdot \frac{P}{P_{\text {std. }}} \cdot \frac{T_{\text {std. }}}{T}$.

In most reported cases, either reducing the SV or increasing pressure increases the production rate, which results from an increase in $\theta$. One study [6] indicated that lowering the SV to prolong the interaction between the reactants and the catalyst led to further hydrogenation and oligomerization of short-chain hydrocarbons, which resulted in an increase in long chain $\left(\mathrm{C}_{5+}\right)$ products that were more paraffinic.

Frequent shut-downs and start-ups of industrial FT reactors to replace spent catalyst adversely affect the profitability of an FT production plant. Implementing control system to alter the operating parameters, i.e., pressure and SV, to maintain the conversion (or product formation rate) is sometimes implemented. The choice of the parameters, either individual parameters, or in combinations, to maintain the yield and delay the replacement of the catalyst, is therefore of interest.

In an earlier investigation done by the researchers of this study [2], the results showed that FTS using an iron catalyst at low pressure ( 1.85 bar absolute) has fairly significant catalytic activity for the synthesis of hydrocarbons for TOS up to $1000 \mathrm{~h}$ at a temperature of $250{ }^{\circ} \mathrm{C}$. In this study, the FT reaction was studied over a long period of time (more than 19 months), during which time the gas hourly space velocity (GHSV) and the pressure were varied and the catalyst activity and selectivity monitored. Three different experiments were run in parallel: an iron catalyst was reduced with three different reducing gases, namely $\mathrm{CO}, \mathrm{H}_{2}$ and syngas. The activity and selectivity of the three catalysts were monitored for around 14,000 $\mathrm{h}$ TOS to ascertain how the three differently reduced iron catalysts responded to changes in operating condition over an extended period of time.

There is no, or very little, data available publicly on catalyst performance for long TOS, and thus these data should be of general interest. We are in particular interest to use these data for the conceptual design of a small-scale mobile waste-to-liquid plant, as the performance of the catalyst for long TOS is one of the most important parameters in determining the economics of such processes.

\section{Experimental procedure}

The experimental procedure presented in this study is similar to that used in the previous study done by the researchers [2]. A propriety iron-based catalyst $\left(\mathrm{FeCuKSiO}_{2}\right)$ of the Materials and Process Synthesis research group (MaPS) which is now known as Institute for the Development of Energy for African Sustainability (IDEAS) at the University of South Africa was used. The BET characteristics of the catalyst are indicated in Table 1.

The gases required for FT synthesis, were supplied by African Oxygen (AFROX Ltd), in standard gas cylinders $(40 \mathrm{~kg}$ ) for use in the laboratory. This included the carrier gases and the auxiliaries (argon, helium, hydrogen and air) used for gas chromatography (GC) operations, which required ultra-high purity (UHP) grades (>99.9997\%). Three types of catalyst-reducing gases were used for the catalyst activation: (1) UHP $\mathrm{H}_{2}$; (2) UHP CO; (3) syngas, with a molar composition of $\mathrm{H}_{2} / \mathrm{CO} / \mathrm{N}_{2}=60 \% / 30 \% / 10 \%$. The syngas was also used as feed to the FT reactors during synthesis. The online $\mathrm{GC}$ was calibrated by means of a gas mixture comprising $\mathrm{H}_{2}, \mathrm{CO}, \mathrm{CO}_{2}, \mathrm{~N}_{2}, \mathrm{CH}_{4}, \mathrm{C}_{2} \mathrm{H}_{4}$, and $\mathrm{C}_{2} \mathrm{H}_{6}$.

Table 1 BET characteristics of the catalyst used

\begin{tabular}{ll}
\hline Surface area & Values \\
\hline $\begin{array}{l}\text { Single point surface area at } P / \mathrm{Po}=0.199 \\
\text { BET surface area }\end{array}$ & $148.40 \mathrm{~m}^{2} / \mathrm{g}$ \\
$\quad$ BJH adsorption cumulative surface area of pores & $153.52 \mathrm{~m}^{2} / \mathrm{g}$ \\
$\quad$ between $1.7 \mathrm{~nm}$ and $300.0 \mathrm{~nm}$ diameter & $160.26 \mathrm{~m}^{2} / \mathrm{g}$ \\
BJH desorption cumulative surface area of pores & \\
$\quad$ between $1.7 \mathrm{~nm}$ and $300.0 \mathrm{~nm}$ diameter & $192.72 \mathrm{~m}^{2} / \mathrm{g}$ \\
Pore volume & \\
$\quad \begin{array}{l}\text { Single point adsorption total pore volume of pores } \\
\text { less than } 447.83 \text { nm diameter at P/Po=0.996 }\end{array}$ & $0.42 \mathrm{~cm}^{3} / \mathrm{g}$ \\
BJH adsorption cumulative volume of pores & \\
$\quad$ between 1.7000 nm and 300.0000 nm diameter & $0.44 \mathrm{~cm}^{3} / \mathrm{g}$ \\
BJH desorption cumulative volume of pores & \\
$\quad$ between $1.7 \mathrm{~nm}$ and 300.0 nm diameter & $0.45 \mathrm{~cm}^{3} / \mathrm{g}$ \\
Pore size & \\
Adsorption average pore width (4 V/A by BET) & $10.83 \mathrm{~nm}$ \\
BJH adsorption average pore diameter (4 V/A) & $10.92 \mathrm{~nm}$ \\
BJH desorption average pore diameter (4 V/A) & $9.43 \mathrm{~nm}$ \\
\hline
\end{tabular}




\section{Reactor system}

The experimental set-up consisted of three laboratory scale fixed bed reactors in a parallel configuration (see Fig. 1). An important aspect of the parallel concept was that it enabled all three reactors to share the same feed cylinder, nitrogen and analysis equipment, thereby reducing the possibility of errors. The same feed (syngas) was distributed to the three reactors using Brooks mass flow controllers (Brooks Instrument 5850). A non-return valve was mounted after each mass flow control (MFC) channel to prevent the products from flowing back to the MFC. Besides the lines used to feed the system with syngas, other lines were available to supply gases (such as nitrogen and reducing gases) to the reactors. Back pressure regulators were manually controlled to keep the reactor pressure at a desired set point.

\section{Characterization}

The samples were characterized by X-ray powder diffraction (XRD) and High Resolution Transmission Electron Microscopy (HRTEM). XRD patterns were obtained using a Rigaku XRD instrument equipped with a scintillation counter detector $(40 \mathrm{kV}, 30 \mathrm{~mA})$. The powder samples were scanned in the $0^{\circ}-75^{\circ} 2 \theta$ range at the rate of $0.2^{\circ} / \mathrm{min}$.
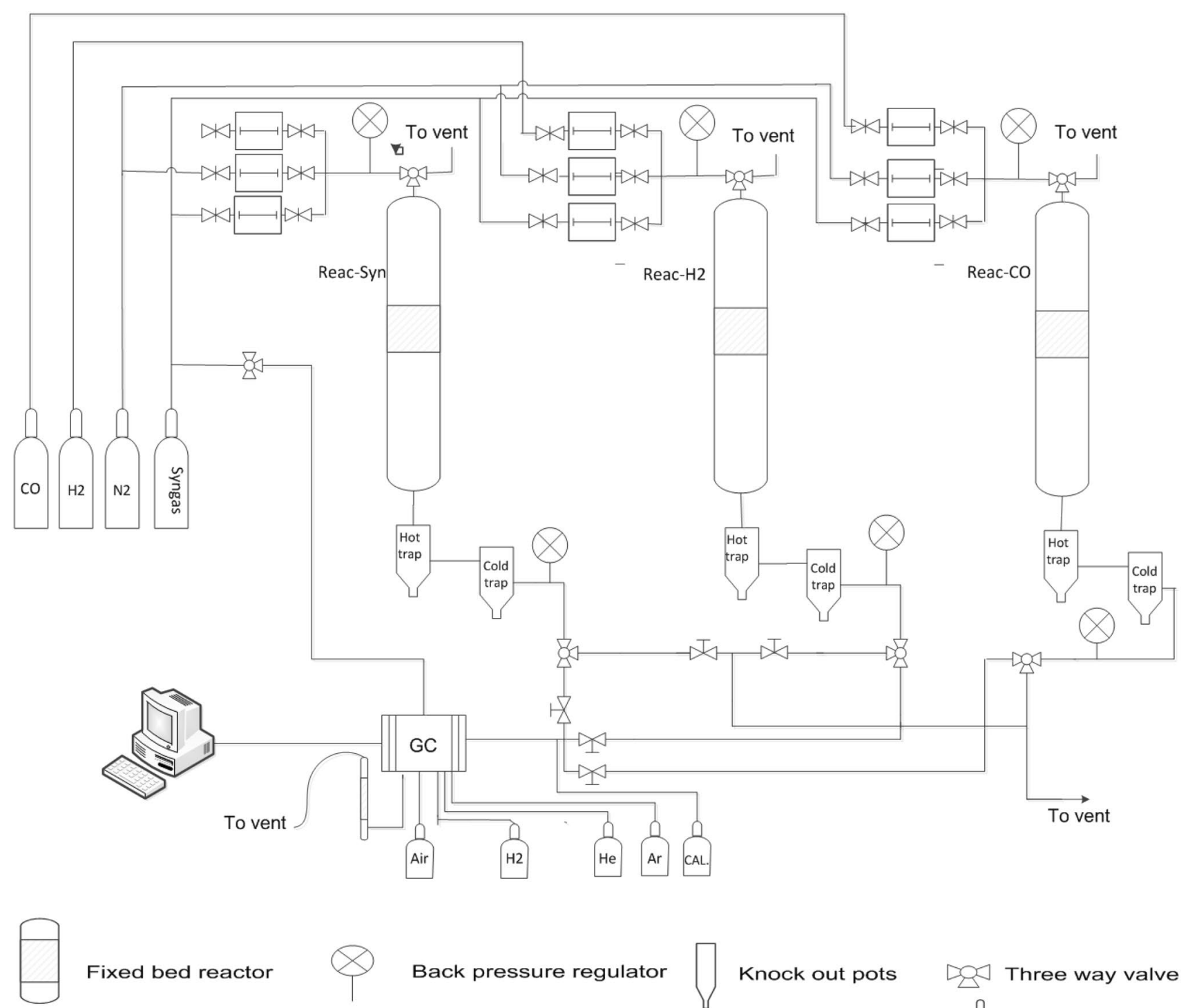

Fixed bed reactor

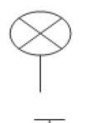

Back pressure regulator

Knock out pots

Three way valve

$D *$ Non return valve

D Two way valve

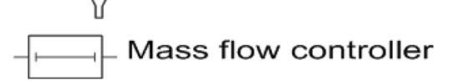

Gas Cylinder

Fig. 1 Flow scheme of the laboratory scale Fischer-Tropsch rig with three fixed reactors in parallel 
High resolution transmission electron micrographs were collected using an FEI Tecnai G2 20 field emission gun (FEG) TEM, which was operated in bright field mode at an accelerating voltage of $200 \mathrm{kV}$. The analysis was performed on the fresh, unreduced catalyst and on all three spent catalysts.

\section{Catalyst reduction procedure}

1 gram of the iron-based catalyst was loaded into each of the three reactors. Before catalyst reduction, the catalyst in each of the reactors was dried under the flow of nitrogen at gas hourly space velocity (GHSV) of $2592 \mathrm{~h}^{-1}$, at a temperature of $120^{\circ} \mathrm{C}$, and at atmospheric pressure $(0.85 \mathrm{bar})$. This was done for $2 \mathrm{~h}$, to remove any moisture in the catalyst. After the drying was completed, catalyst reduction began. Three different reducing agents were used for the catalyst reduction, i.e., syngas for the catalyst reduction in reactor 1 (Reac-Syn); $\mathrm{H}_{2}$ for catalyst in reactor 2 (Reac$\mathrm{H}_{2}$ ); $\mathrm{CO}$ for reactor 3 (Reac-CO). The three types of reducing gases were introduced into the three reactors, respectively, at a GHSV of $2592 \mathrm{~h}^{-1}$, at atmospheric pressure (0.85 bar), and the temperature was increased from $120^{\circ} \mathrm{C}$ (drying temperature) to $250{ }^{\circ} \mathrm{C}$ (reduction temperature) at a heating rate of $1{ }^{\circ} \mathrm{C} / \mathrm{min}$. The system was left at $250{ }^{\circ} \mathrm{C}$ in the atmosphere of reducing agents for $48 \mathrm{~h}$, prior to running the FT reaction.

\section{Experimental conditions}

The FT operating conditions were initially kept at a reactor pressure of 1.85 bar (absolute), a temperature of $250{ }^{\circ} \mathrm{C}$ and syngas gas feed at a GHSV of $2592 \mathrm{~h}^{-1}$ for about $5000 \mathrm{~h}$ TOS. Thereafter, various changes were made to the GHSV and pressure at different TOS. The aim was to test the responses of the catalysts to changes in the operating conditions at long TOS. The series of tests intended to identify the best reducing agent in terms of long-term catalyst activity, selectivity, stability and resistance to deactivation. The conditions at various TOS and selected results are summarized in Table 2. Data were obtained at three GHSV $\left(2592-1296 \mathrm{~h}^{-1}\right.$, then $\left.648 \mathrm{~h}^{-1}\right)$ and three pressures $[P=1.85,10.85$ and 20.85 bar $(\mathrm{abs})]$.

The data obtained from 0 to $1000 \mathrm{~h}$ TOS were previously reported by the researchers [2]; the inclusion of these data in this article is intended to provide readers with a full picture of the effect of operating conditions on FTS over a TOS from 0 to ca. $14,500 \mathrm{~h}$.
Table 2 Summary of operating conditions (pressure and GHSV) used at different TOS

\begin{tabular}{llll}
\hline GHSV $\left(\mathrm{H}^{-1}\right)$ & Pressure $($ bar abs $)$ & \multicolumn{2}{l}{ Range TOS $(\mathrm{h})$} \\
\cline { 3 - 4 } & Reac-SYN & From & To \\
\hline 2592 & 1.85 & 0.00 & 6060.57 \\
1296 & 1.85 & 6089.66 & 6277.58 \\
648 & 1.85 & 6284.49 & 6816.84 \\
2592 & 1.85 & 6820.12 & $13,676.04$ \\
2592 & 10.85 & $13,676.04$ & $13,382.51$ \\
2592 & 20.85 & $13,987.08$ & $14,340.29$ \\
REAC-H & & & \\
2592 & 1.85 & 0.00 & 5889.17 \\
1296 & 1.85 & 5901.12 & 6051.85 \\
648 & 1.85 & 6113.13 & 6630.27 \\
2592 & 1.85 & 6632.21 & $13,116.80$ \\
2592 & 10.85 & $13,724.55$ & $13,979.95$ \\
2592 & 20.85 & $13,984.70$ & $14,132.18$ \\
REAC-CO & & & \\
2592 & 1.85 & 0.00 & 5355.36 \\
1296 & 1.85 & 5402.24 & 5567.91 \\
648 & 1.85 & 5577.81 & 6084.79 \\
2592 & 1.85 & 6110.13 & $12,892.23$ \\
2592 & 10.85 & $13,112.81$ & $13,382.26$ \\
2592 & 20.85 & & $13,636.04$ \\
\hline
\end{tabular}

Reac-Syn refers to the catalyst reduced with Syngas $\left(\mathrm{H}_{2} / \mathrm{CO} /\right.$ $\mathrm{N}_{2}=60 \% / 30 \% / 10 \%$ ); Reac- $\mathrm{H}_{2}$ refers to the catalyst reduced with $\mathrm{H}_{2}$ and Reac-CO refers to the catalyst reduced with $\mathrm{CO}$

The temperature was held at $250{ }^{\circ} \mathrm{C}$ for three reactors

\section{Product separation and analysis}

The products exiting the reactor were cooled and collected as different fractions at different temperatures. The wax products were collected in the hot trap maintained at $150{ }^{\circ} \mathrm{C}$. The liquid products were accumulated in the cold trap, which was kept at room temperature. The components that were not condensed, i.e., were gaseous at room temperature, were directed to the online gas chromatography (GC) for analysis and/or venting.

The product analysis was done through three different detectors: a flame ionization detector (FID) and two thermal conductivity detectors (TCDs). Of the two TCD detectors used in the online $\mathrm{GC}$, TCD-A was used to analyze $\mathrm{CH}_{4}, \mathrm{CO}_{2}, \mathrm{~N}_{2}$ and $\mathrm{CO}$ with UHP He as a carrier gas, while TCD-B was used to analyze $\mathrm{H}_{2}$ with UHP Ar as a carrier gas using Teknokroma molecular sieve columns.

Varian capillary columns were used in this FID system for the analysis of gaseous olefin and paraffin products $\left(\mathrm{C}_{1}-\mathrm{C}_{5}\right)$. Samples from the tail gas were taken every $83 \mathrm{~min}$ via valves from the sampling loop. The excess gas from the sampling 
loop passed through a bubble meter to the vent. The tail gas from the three reactors was sampled cyclically (reactor 1-2-3:1-2-3 cycles).

$\mathrm{CO}$ conversions, $\% \mathrm{CO}$, were calculated as follows:

$\% \mathrm{CO}=\frac{F_{\mathrm{in}} X_{\mathrm{co}, \text { in }}-F_{\text {out }} X_{\mathrm{co}, \text { out }}}{F_{\mathrm{in}} X_{\mathrm{co}, \text { in }}}$,

where $X_{\text {co,in }}$ and $X_{\text {co,out }}$ are the molar fractions of $\mathrm{CO}$ in the reactor inlet and outlet, respectively, $F_{\text {in }}$ and $F_{\text {out }}$ are the molar flow rates of gas in and out of the reactor, respectively.

The CO consumption rate, ( $\mathrm{mol} /(\mathrm{min} \cdot \mathrm{gcat}))$, was calculated as follows:

$r_{\mathrm{CO}}=\frac{F_{\text {out }} X_{\mathrm{co}, \text { out }}-F_{\text {in }} X_{\mathrm{co}, \text { in }}}{m_{\mathrm{cat}}}$,

where $m_{\text {cat }}$ is the mass of the catalyst used in this reaction, in grams.

The rate of formation of product $\theta_{i}, \mathrm{~mol} /\left(\mathrm{min} \cdot \mathrm{g}_{\text {cat }}\right)$ is given by

$r_{\varphi_{i}}=\frac{F_{\text {out }} X_{\varphi_{i}, \text { out }}}{m_{\text {cat }}}$,

where $X_{\varphi_{i} \text {,out }}$ is the molar fraction of $\varphi_{i}$ in the reactor outlet gas stream.The product selectivity for species $\varphi_{i}, \operatorname{Sel}\left(\varphi_{i}\right)$ is calculated on a moles of carbon basis, as follows:

$\operatorname{Sel}\left(\varphi_{i}\right)=\frac{[n C]_{\varphi_{i}}}{-r_{\mathrm{co}} \times t \times m_{\mathrm{cat}}}$,

where $[n C]_{\varphi_{i}}$ are the moles of carbon in species $\varphi_{i}$ contained in a sample of the exit of reactor collected over time $t$.
Results and discussion

\section{Characterization of fresh and spent catalysts}

\section{XRD}

The XRD patterns of the three differently reduced spent catalysts at TOS ca. $14,500 \mathrm{~h}$ and that of the fresh catalyst are shown in Fig. 2. The spectra show the differences in the phases existing in each of the three differently reduced catalysts and also the phases that existed in the fresh catalyst.

The fresh catalyst produced only one peak corresponding to magnetite, whereas the used catalyst indicated the presence of several phases, with graphitic carbon being dominant. Magnetite is a known water gas shift catalyst [7]. The iron carbide phases remaining in the deactivating catalyst might provide a reason for the rise in $\mathrm{C}_{1}-\mathrm{C}_{4}$ selectivities consequent on the decrease in GHSV, i.e., it may be attributable to a longer residence time. The presence of graphitic carbon might have hindered $\mathrm{C}_{5+}$ re-adsorption and diffusion, both inside and outside of the catalyst pores, hence a decrease in $\mathrm{C}_{5+}$ selectivity.

\section{HRTEM}

To give further insight, both fresh and spent catalysts were subjected to characterization via HRTEM analysis. Figure 3 depicts images of (a) fresh catalyst, (b) spent catalyst from Reac-Syn, (c) spent catalyst from Reac- $\mathrm{H}_{2}$, (d) spent catalyst from Reac-CO, (e) HRTEM of the fresh catalyst and (f) the plot profile (ImageJ software) of the distance between two lattice fringes of the fresh catalyst. The HRTEM micrographs shown in Fig. 3a-d as inserted pictures allow for
Fig. 2 XRD spectra of the fresh catalyst and spent catalyst from different reactors after ca $14,500 \mathrm{~h}$ of TOS

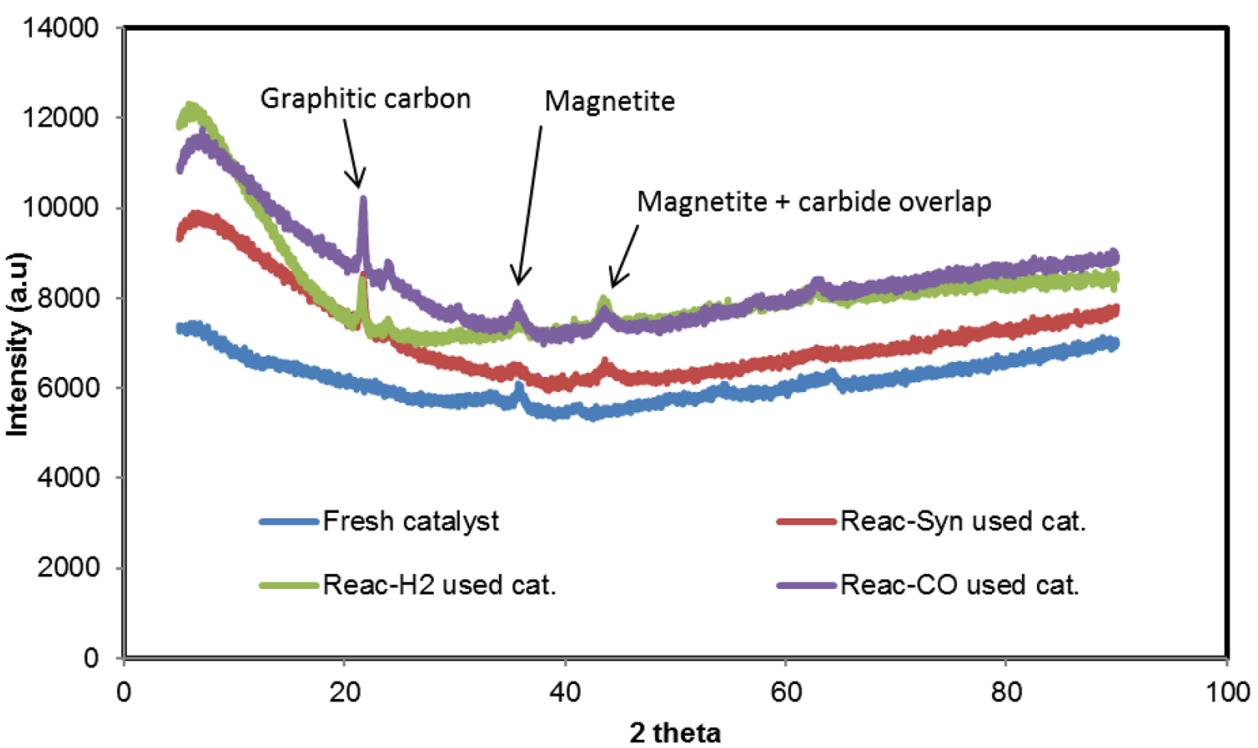



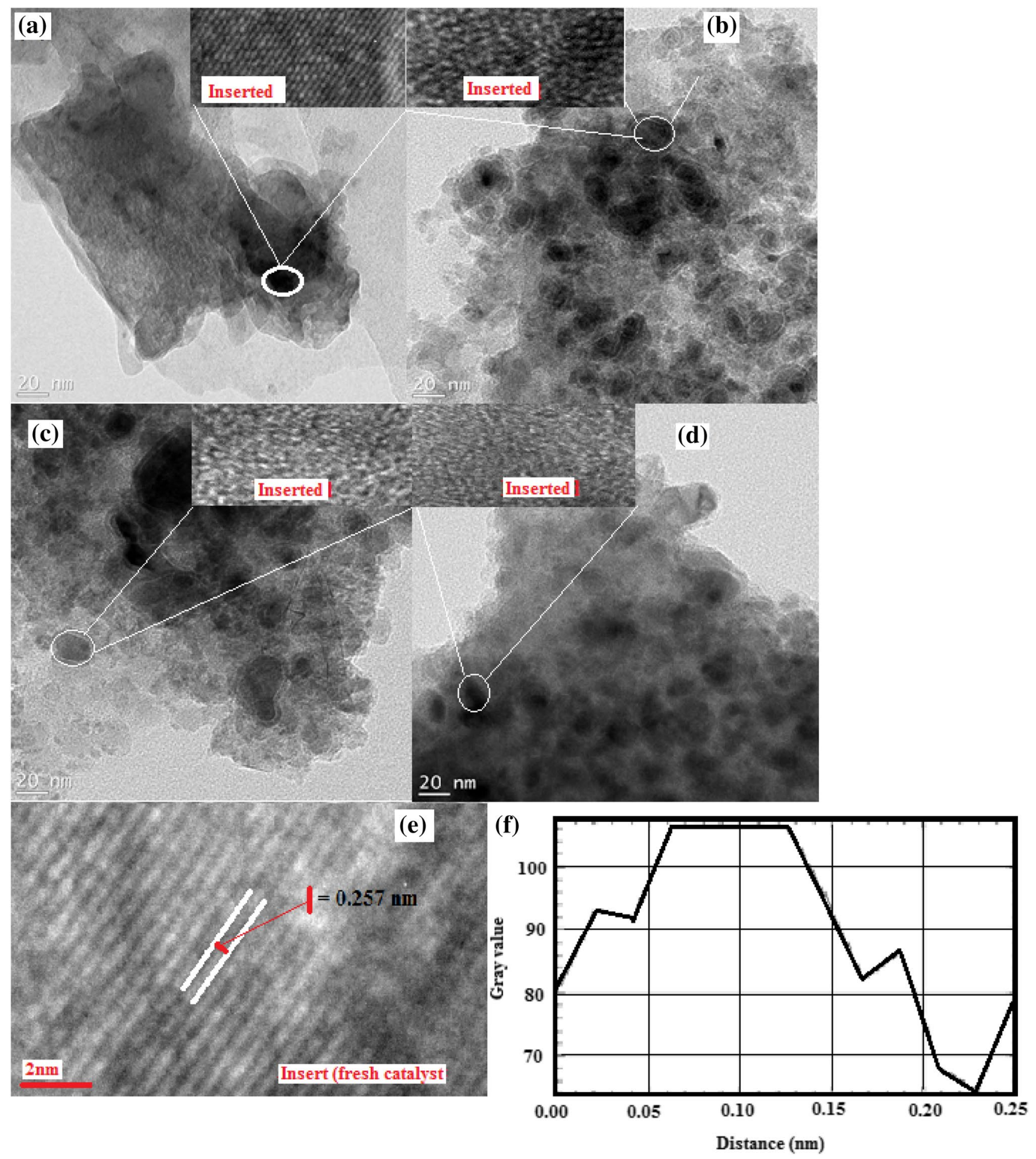

Fig. 3 TEM images of a fresh catalyst, b spend catalyst from Reac-Syn, c spent catalyst from Reac- $\mathrm{H}_{2}$, d spent catalyst from Reac-CO, e HRTEM of the fresh catalyst and $\mathbf{f}$ plot profile of two lattice fringes from image $\mathbf{e}$ using ImageJ software

identification of the growth of graphitic carbon from all the spent catalysts in each of the three reactors (see dimming of the light in Fig. 4). The presence of carbon deposits is confirmed by the XRD patterns in Fig. 2. Carbon deposition is one of the supported metal catalyst deactivation routes; it is responsible for blocking of surface sites, metal crystallite 
encapsulation, plugging of pores, and destruction of catalyst pellets by carbon filaments [8,9]. This deposition of carbon affects the diffusion of heavy olefins and paraffins both inside and outside the catalyst pores or surface and GHSV becomes an important factor. However, the effect may not be as pronounced in light hydrocarbons, which have almost the same volatilities and hence are not influenced by the diffusion limitations [10].

Furthermore, the crystallinity of the fresh iron catalyst is confirmed by the HRTEM image (Fig. 3e) which visibly displays the presence of lattice fringes distribution. The analysis of the lattice fringes was then rendered possible with ImageJ software. The measurement of the value between the two lattice fringes was obtained $(0.251 \mathrm{~nm})$ with the plot profile analysis using ImageJ software. The obtained value, $0.251 \mathrm{~nm}$, approximates value reported in the literature of $0.253 \mathrm{~nm}$ [11]. Researchers [11] have reported that the value (approximately $0.25 \mathrm{~nm}$ ) of the distance between two lattice fringes corresponds to the (311) plane of the magnetite crystal. XRD patterns have also confirmed the presence of magnetite in all four samples (fresh and spent catalysts). It is interesting to see that the selected area electron diffraction (SAED) patterns highlight the difference between the three used catalysts and the fresh catalyst when the analysis is focused on the appearance of the rings in Fig. 4 which indicate the polycrystalline phases of the particles. It is remarkable that the polycrystalline phases of the particles decrease in the spent catalysts, most likely due the deposition of carbon during FT reaction after a long TOS.

\section{Effect of process parameters on the product distribution}

The effect of process parameters on the activity and hydrocarbon selectivity was studied under the experimental conditions described in Table 2. We will consider the various conditions that are described in Table 2 separately and then later compare the results.
Fig. 4 Selected area electron diffraction (SAED) pattern of a fresh catalyst, b Reac-Syn spent catalyst, c Reac- $\mathrm{H}_{2}$ spent catalyst and $\mathbf{d}$ Reac-CO spent catalyst

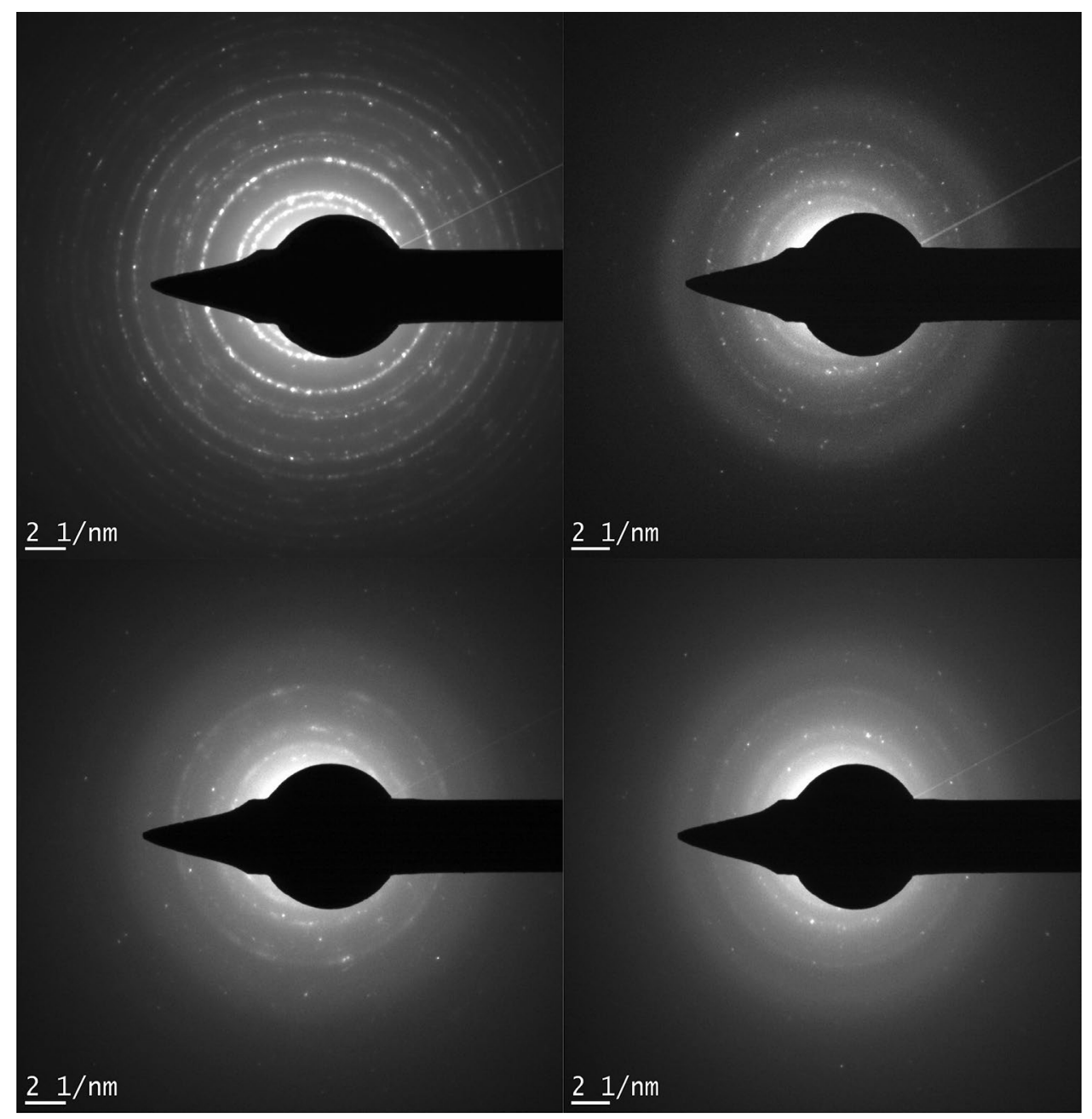




\section{Effect of TOS on the CO conversation; TOS $<5000 \mathrm{~h}$}

In this study, the experiment included several stages. Initially, the synthesis was done at $250{ }^{\circ} \mathrm{C}$ for about 5000-6000 $\mathrm{h}$ TOS at fixed pressure (1.85 bar abs) and GHSV (2592 h-1); at this stage, the conversion for all three catalysts dropped from around $22-15 \%$ to Reac-syn-6.03\%; Reac- $\mathrm{H}_{2}-6.99 \%$; Reac-CO 4.36\%. The results of these experiments are presented in Fig. 5. The data show that the $\mathrm{CO}$ conversion for all three reduced catalysts decreases with an increase in TOS, indicating that the catalyst deactivated with time as expected.

\section{Effect of GHSV on conversion}

The GHSV was then decreased from 2592 to $1296 \mathrm{~h}^{-1}$, while maintaining the pressure at 1.85 bar (abs) as described in Table 2 . The three differently reduced catalysts responded positively to the reduction in feed gas flow rate as shown in Fig. 6, with conversion increasing in all three cases. However, the responses were of different magnitudes: Reac-Syn showed the highest response a 2.31-fold increase from GHSV $2592-1296 \mathrm{~h}^{-1}$; Reac- $\mathrm{H}_{2}$ showed a 1.77 -fold increase; Reac-CO showed a 1.69-fold increase.

A further halving in flow rate to a GHSV of $648 \mathrm{~h}^{-1}$ did not yield quite as much of a difference in the conversion. For example, from 1296 to $648 \mathrm{~h}^{-1}$, the conversion
Fig. 5 Effect of TOS on CO conversion of differently reduced catalysts at a pressure of 1.85 bar (abs), GHSV of $2592 \mathrm{~h}^{-1}$ and temperature of $250{ }^{\circ} \mathrm{C}$ with standard deviation error bars
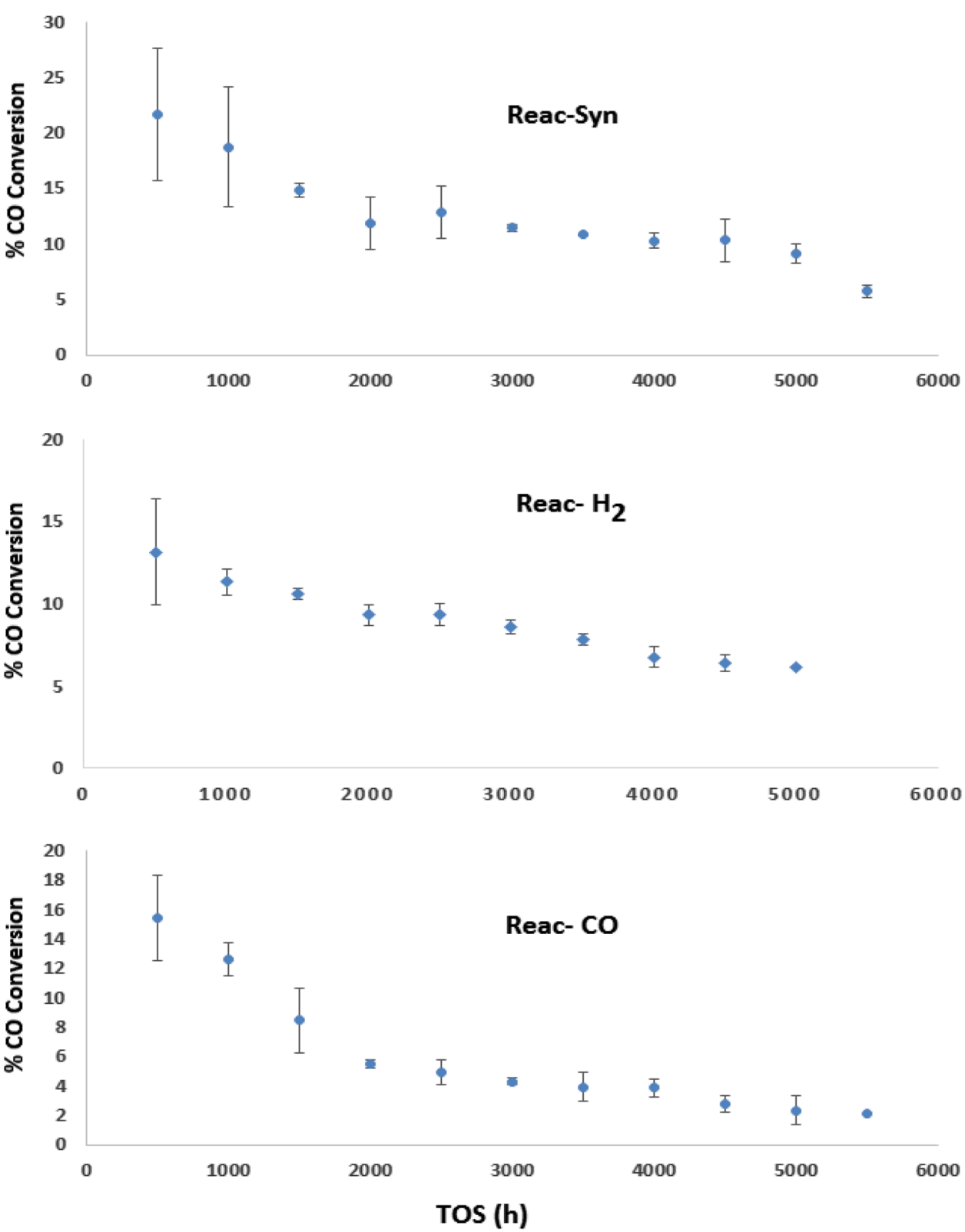
Fig. 6 Conversions of differently reduced reactors with changing GHSV: a Reac-Syn; b Reac- $\mathrm{H}_{2}$, c Reac-CO. Reactor temperature was maintained at $250{ }^{\circ} \mathrm{C}$ and reactor pressure at 1.85 bar (abs)
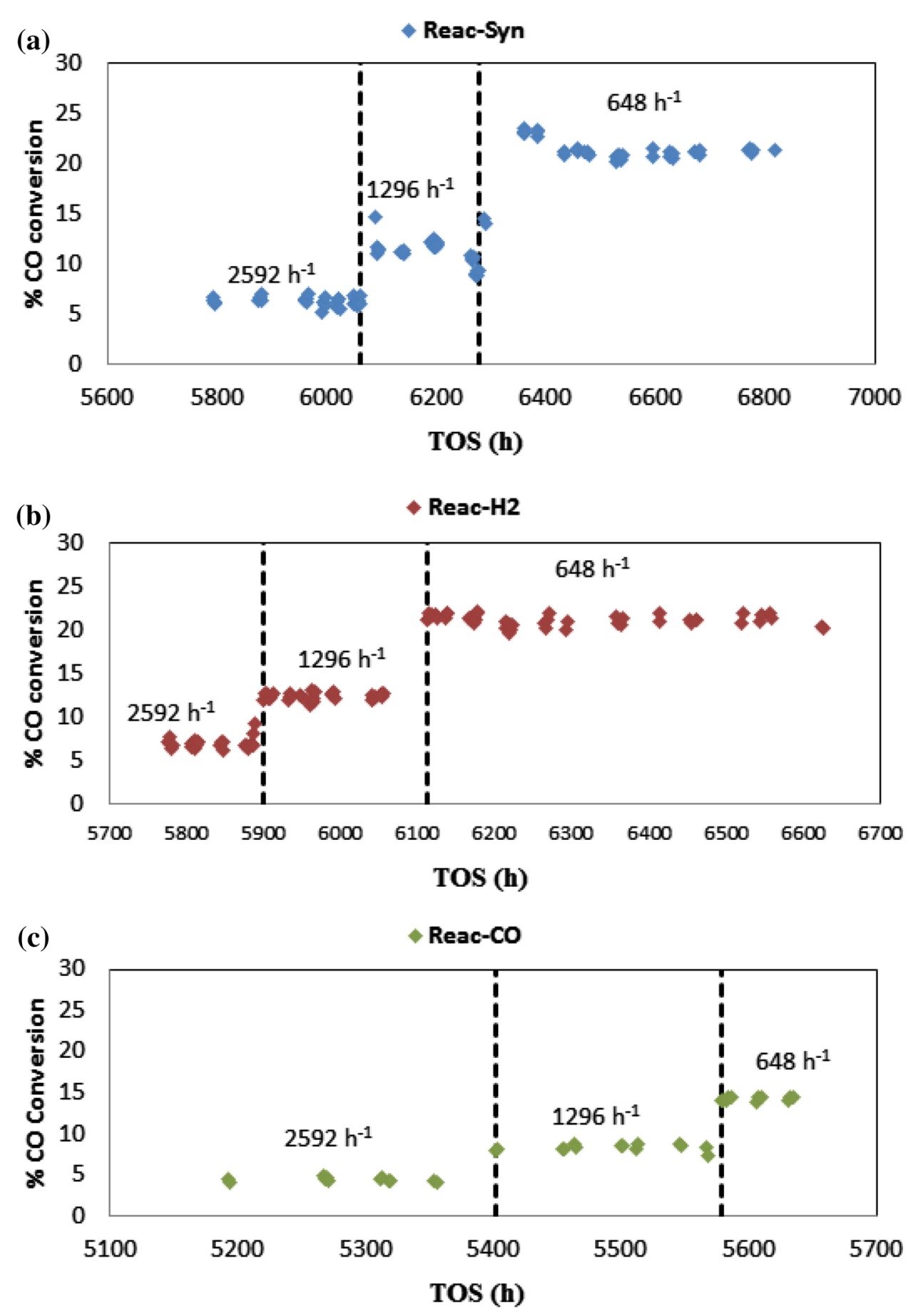

of Reac-Syn increased from 9.86 to $17.20 \%$ (a 1.74-fold increase), Reac- $\mathrm{H}_{2}$ increased from 12.35 to $20.97 \%$ (a 1.70fold increase); Reac-CO increased from 7.34 to $10.18 \%$ (1.39-fold increase). Thus, in terms of conversion, the performance of the Reac-CO reactor performed significantly worse than the other two reactors.

Table 3 provides a summary of one-way ANOVA results that compare $\mathrm{CO}$ conversion obtained from three reactors. To enable a comparison of the response to changes in GHSV, a post-hoc Bonferroni correction test was performed, and the results tabulated. As shown in all ANOVA tables, the $P$ values are small, which provides strong evidence that the three reactors responded differently to changes in GHSV. 
Table 3 Statistical analysis of conversion at different GHSV for three differently reduced catalysts

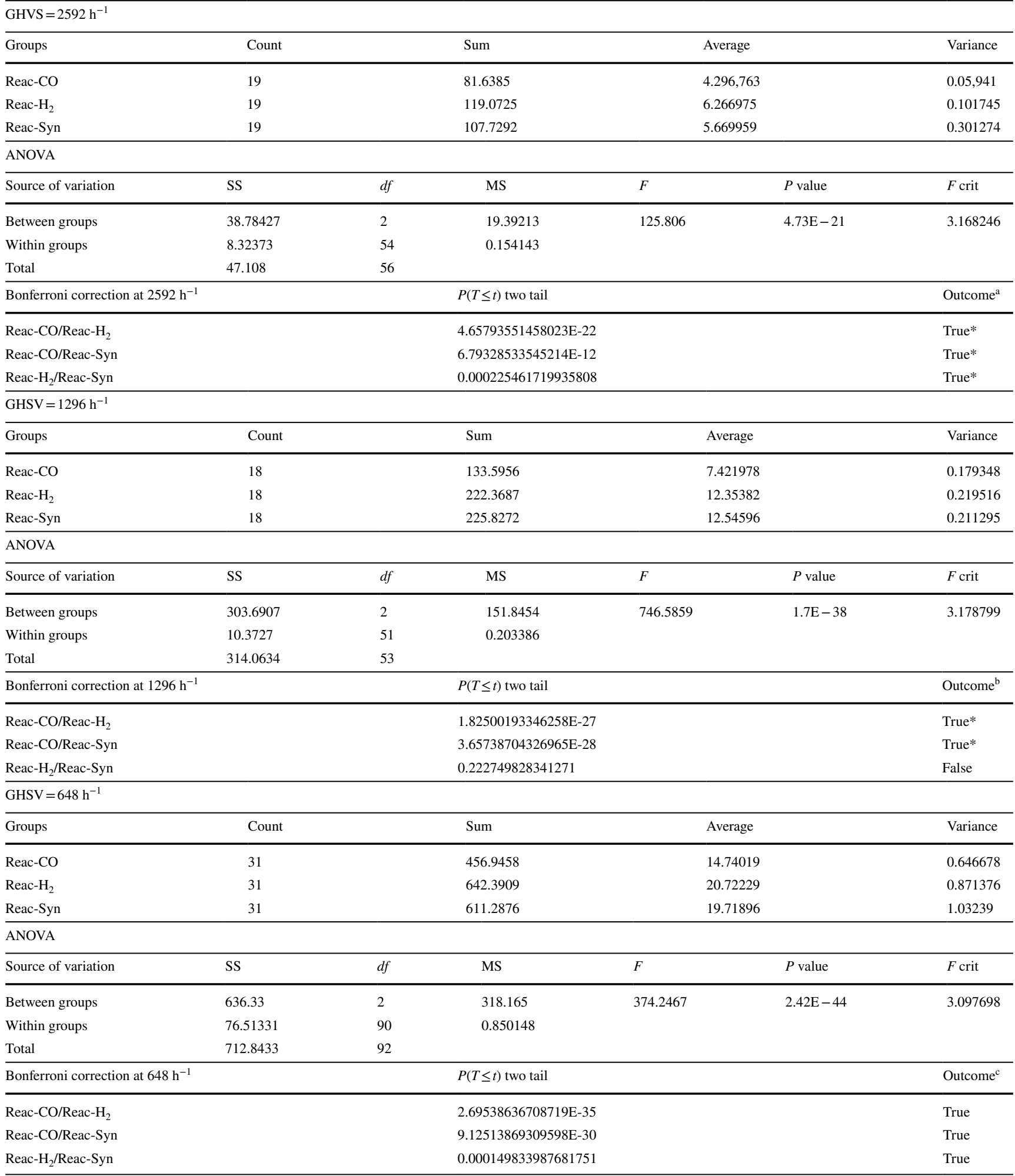

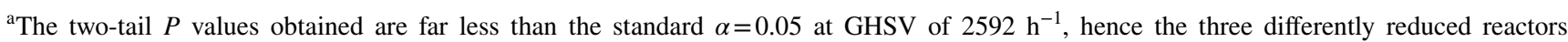
responded differently

${ }^{\mathrm{b}}$ The Reac-CO/Reac- $\mathrm{H}_{2}$ and Reac-CO/Reac-Syn gave a two-tail $P$ values that are far less than the standard $\alpha=0.05$ at GHSV of $1296 \mathrm{~h}^{-1}$, suggesting a significant difference in terms of CO conversion. The Reac-H2/Reac-Syn reactors did not yield a significant difference at this particular GHSV

${ }^{\mathrm{c}}$ The ANOVA analysis suggested a significant difference at $648 \mathrm{~h}^{-1}$ for all the reactors, and a Bonferroni corrected post hoc $t$ test affirmed the difference that GHSV yielded significantly different $\mathrm{CO}$ conversions 


\section{Effect of GHSV on hydrocarbon selectivity}

The products' distribution of hydrocarbons formed at the various GHSV are summarized in Table $4 \mathrm{a}-\mathrm{c}$ for the light olefins, light paraffins, total (i.e., olefin and paraffin) light hydrocarbons and $\mathrm{C}_{5+}$ fraction, for all three reactors. The results are shown as averages in the tables as these are simple to see and interpret.

The selectivity to paraffins was observed to increase with the decrease in GHSV, while the selectivity towards olefins tended to follow the same pattern, except for the discrepancies of $\mathrm{C}_{2}$ olefin for Reac-Syn and Reac- $\mathrm{H}_{2}$. In general, the lighter hydrocarbons increased in selectivity with decrease in the GHSV, whereas the selectivity towards $\mathrm{C}_{5+}$ (heavy hydrocarbons) decreased with decreasing GHSV. The observed $\mathrm{C}_{5+}$ trend is different to the normal trend observed in the literature, for example [12]. As the GHSV is decreased, the reactant-catalyst contact time increased hence increasing time for secondary reactions to occur (Eq. 1) which would suggest that hydrogenation and chain growth is favored resulting in a heavier product distribution. This is not what is observed at long TOS. The water gas shift (WGS) reaction could be favored relative to FTS, as this reaction is known to be catalyzed by the magnetite [8]. This would result in a decrease in hydrocarbon selectivity with TOS.

This potentially has a big impact on the design of the proposed mobile small-scale biomass/waste to liquid process. When such a process is designed to run at low pressure [such as 1.85 bar(abs), as in this study], one will need to balance a higher conversion which is achieved at lower GHSV's against the increase to lighter hydrocarbons that occurs at lower GHSV's. The information in Table 4 shows that both olefin and paraffin selectivities increase with a decrease in GHSV.

\section{Effect of GHSV on WGS and $\mathrm{CH}_{4}$ selectivity}

The $\mathrm{CH}_{4}$ selectivity was not very sensitive to GHSV, whereas the $\mathrm{CO}_{2}$ selectivity increased significantly with decreasing GHSV (see Fig. 7). The averaged results of Fig. 7 are summarized in Table 5 for ease of interpretation.

\section{Effect of pressure on the $\mathrm{CO}$ conversion}

The system pressure was varied and the $\mathrm{CO}$ conversion was measured; the results are shown in Fig. 8 under the experimental procedure in Table 2 for TOS starting from 12,000 to $14,100 \mathrm{~h}$. CO conversion increased with increasing pressure for all the differently reduced catalysts as expected. As summarized in Table 6, the CO conversion increased 2.54-fold, 3.81-fold and 5.34-fold for Reac-Syn, Reac- $\mathrm{H}_{2}$ and Reac-CO reduced reactors, respectively, when pressure was increased from 1.85 to 10.85 bar (abs). When pressure was further increased from 10.85 to 20.85 bar (abs), Reac-Syn showed the largest increase of 2.17 -fold followed by the Reac-CO (with a 1.75 -fold), and finally, Reac- $\mathrm{H}_{2}$ (with a 1.56-fold increase).

\section{Effect of pressure on the selectivity to hydrocarbons}

The results are summarized in Table 7 . The effect of pressure on selectivity is complex and selectivity toward the total light hydrocarbons (paraffin + olefin) and $\mathrm{C}_{5+}$ does not seem to be significantly affected by variations in pressure.

Table 7 shows that the selectivity to olefins generally decreased with an increase in the pressure from 1.85 bar (abs) to 20.85 bar (abs), for all three reactors; the selectivity to paraffins in contrast increases with pressure. Observed anomalies occurred in Reac- $\mathrm{H}_{2}$, where $\mathrm{C}_{3}$ and $\mathrm{C}_{5}$ olefins do not follow this trend. The behavior that was noticed could be attributed to the hydrogenation of olefins to paraffins, as this was also observed in other studies $[5,13]$. In general, the results confirm that when the FT reactor pressure is increased, the product selectivity generally increases towards paraffinic products. Paraffinic product means more wax product, and this finding agrees with findings proposed by Farias et al. [14]; they reported that high pressures (25-30 atm) favored the production of waxes, while moderate pressure (e.g., $20 \mathrm{~atm}$ ) showed selectivity towards the diesel fraction.

When compared to the Reac-Syn and Reac- $\mathrm{H}_{2}$ reactors, Reac-CO always showed a larger scale change in terms of selectivity to olefins. The trend is expressed as

Reac- $_{2, \mathrm{O}}<$ Reac-Syn $_{, \mathrm{O}}<$ Reac-CO $_{, \mathrm{O}}$,

where the subscript o refers to olefin.

For paraffins, the following trend is observed:

Reac- $\mathrm{H}_{2, \mathrm{p}}<$ Reac-CO, $_{, \mathrm{p}}<$ Reac-Syn ${ }_{, \mathrm{p}}$,

where the subscript $p$ refers to olefin.

For $\mathrm{C}_{5+}$, at all pressures, the trend is:

Reac- $\mathrm{H}_{2, \mathrm{C} 5}+<$ Reac-CO $_{, \mathrm{C} 5}+<$ Reac-Syn $_{{ }_{\mathrm{C} 5}+}$,

where the subscript $\mathrm{C}_{5+}$ refers to hydrocarbons of chain length 5 or longer.

\section{Effect of pressure on the selectivity to $\mathrm{CH}_{4}$ and $\mathrm{CO}_{2}$ production}

The effect of pressure on the selectivity of $\mathrm{CH}_{4}$ and $\mathrm{CO}_{2}$ was also measured for all three reactors. The results are displayed in Fig. 8a-c and the data are summarized in Table 8. The data show that $\mathrm{CO}_{2}$ selectivity increases slightly with increasing pressure; a slight, but obvious increase in selectivity was seen when the pressure was increased from 1.85 


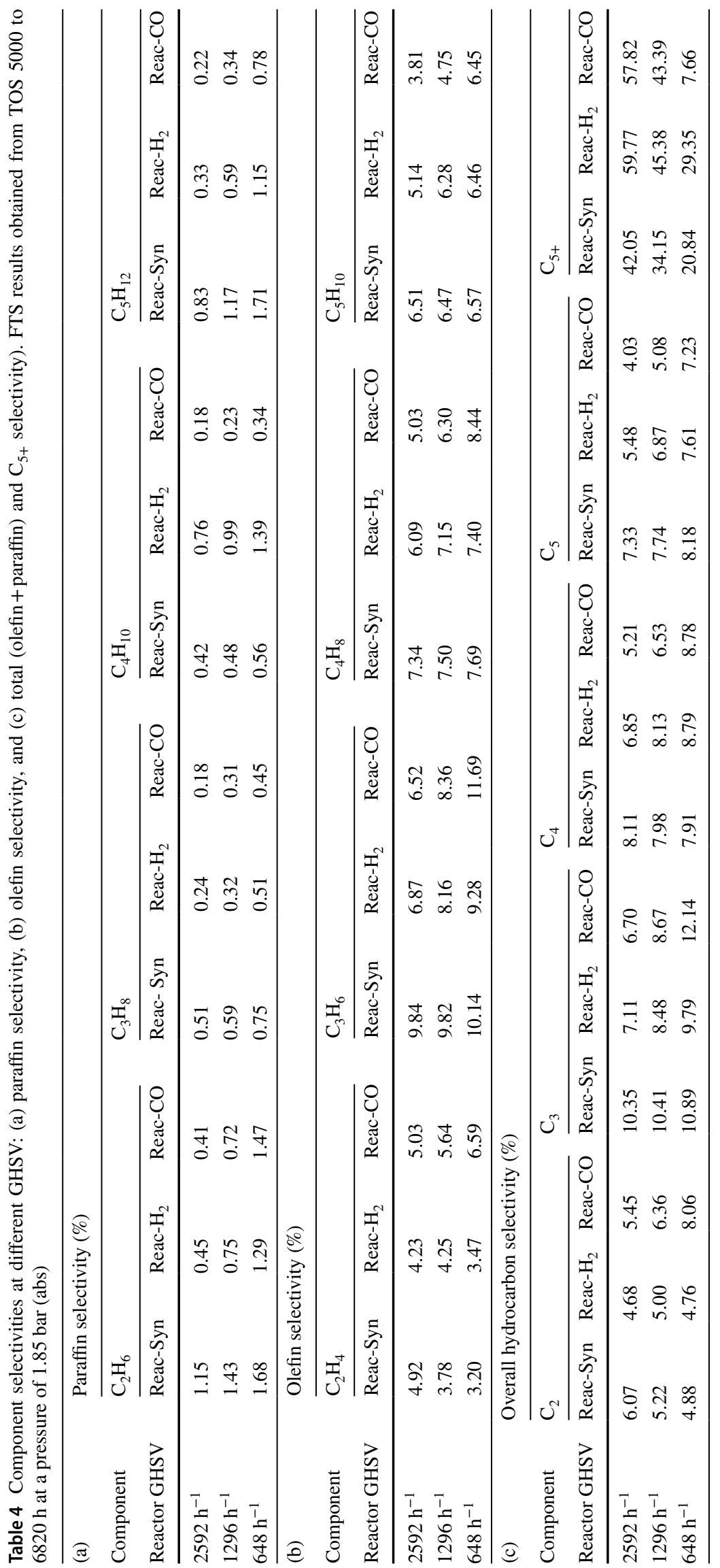


Fig. $7 \mathrm{CO}_{2}$ and $\mathrm{CH}_{4}$ selectivities with reductions in GHSV at different TOS
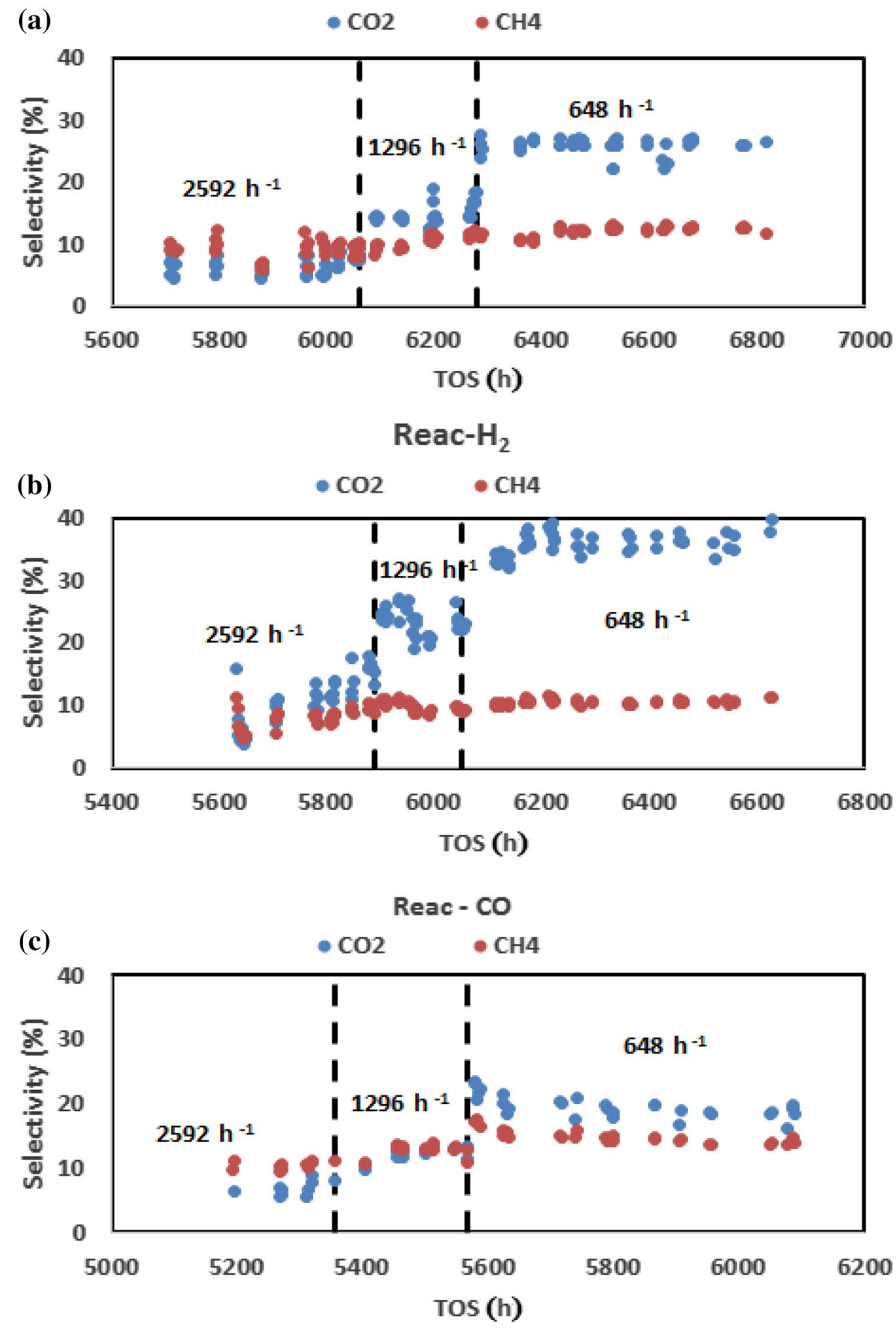

to 10.85 bar (abs), however, the magnitude of increase was much smaller when the pressure was increased from 10.85 to 20.85 bar (abs). The $\mathrm{CH}_{4}$ selectivity remains nearly constant almost the same, except for Reac- $\mathrm{H}_{2}$ which had a low $\mathrm{CH}_{4}$ selectivity at low pressure. Our finding patterns agree with statistical models based on experimental data from the literature [15] (Fig. 9).

The sensitivity with respect to changes in GHSV and pressure for methane is a more difficult case to explain. 
Table 5 Summary of averaged results for $\mathrm{CH}_{4}$ and $\mathrm{CO}_{2}$ selectivity at different GHSV: pressure of 1.85 bar abs, temperature $250{ }^{\circ} \mathrm{C}$ and TOS between 5200 and $6900 \mathrm{~h}$

\begin{tabular}{|c|c|c|c|}
\hline & $2592 \mathrm{~h}^{-1}$ & $1296 \mathrm{~h}^{-1}$ & $648 \mathrm{~h}^{-1}$ \\
\hline \multicolumn{4}{|c|}{$\mathrm{CO}_{2}$ selectivity $(\%)$} \\
\hline Reac-Syn & $6.54 \pm 1.42$ & $14.73 \pm 1.67$ & $25.77 \pm 1.34$ \\
\hline Reac- $\mathrm{H}_{2}$ & $11.59 \pm 3.74$ & $23.43 \pm 2.05$ & $35.79 \pm 1.90$ \\
\hline Reac-CO & $6.88 \pm 1.11$ & $12.29 \pm 1.12$ & $19.63 \pm 1.74$ \\
\hline \multicolumn{4}{|c|}{$\mathrm{CH}_{4}$ selectivity $(\%)$} \\
\hline Reac-Syn & $9.14 \pm 1.38$ & $10.62 \pm 1.04$ & $12.01 \pm 0.73$ \\
\hline Reac- $\mathrm{H}_{2}$ & $7.98 \pm 1.53$ & $9.80 \pm 0.80$ & $10.53 \pm 0.44$ \\
\hline Reac-CO & $10.50 \pm 0.64$ & $12.70 \pm 1.06$ & $15.02 \pm 1.15$ \\
\hline
\end{tabular}

Research suggests that the iron carbides favor the formation of methane $[16,17]$. This prediction is supported based on the calculated reaction energies and effective barriers by [16] using spin-polarized density functional theory calculations that $\mathrm{CH}_{4}$ formation is more favorable on $\mathrm{Fe}_{5} \mathrm{C}_{2}$ and $\mathrm{Fe}_{2} \mathrm{C}$. The XRD analysis of spent catalyst seen in Fig. 2 shows the presence of iron carbide remnants. With this observation, one would expect a significant variation in selectivity with decreasing GHSV and increasing pressure.
Fig. $8 \mathrm{CO}$ conversion versus TOS at pressures of $1.85,10.85$ and 20.85 bar (abs) at temperature $250{ }^{\circ} \mathrm{C}$, GHSV of $2592 \mathrm{~h}^{-1}$, for TOS between 12,000 and $14,400 \mathrm{~h}$
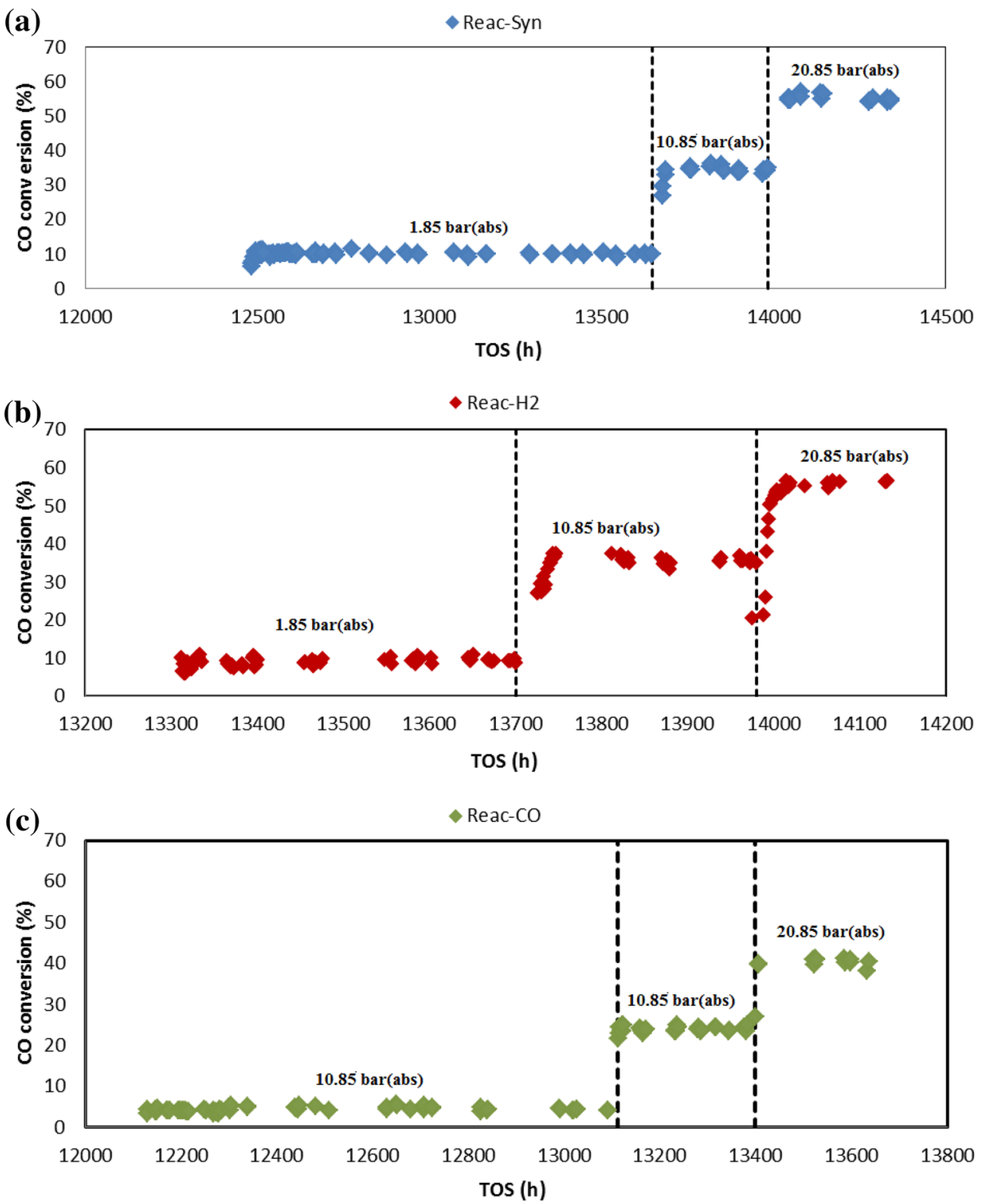
Table 6 Summary of averaged results for CO conversion at various pressures: reaction temperature $250{ }^{\circ} \mathrm{C}$, GHSV of $2592 \mathrm{~h}^{-1}$, for TOS between 12,000 and $14,400 \mathrm{~h}$

\begin{tabular}{llll}
\hline CO conversion (\%) & 1.85 bar (abs) & 10.85 bar (abs) & 20.85 bar (abs) \\
\hline Reac-Syn & $9.99 \pm 1.41$ & $30.42 \pm 2.14$ & $55.71 \pm 3.94$ \\
Reac- $\mathrm{H}_{2}$ & $7.12 \pm 1.71$ & $34.04 \pm 3.80$ & $54.47 \pm 2.96$ \\
Reac-CO & $4.55 \pm 0.29$ & $23.58 \pm 2.14$ & $40.40 \pm 3.90$ \\
\hline
\end{tabular}

\section{Conclusion}

An iron catalyst was reduced with syngas, hydrogen or carbon monoxide. The three differently reduced catalysts were run for long TOS. The product distribution changed due to catalyst speciation as deactivation occurs. At long TOS $(>1000 \mathrm{~h})$, a decrease in GHSV resulted in an increase in light paraffin and olefin selectivities $\left(\mathrm{C}_{1}-\mathrm{C}_{5}\right)$ and a corresponding decrease in $\mathrm{C}_{5+}$ selectivity. This occurred in all three catalysts. This trend is the inverse to what was
Table 8 Summary of the averaged selectivity of $\mathrm{CO}_{2}$ and $\mathrm{CH}_{4}$ at different pressures, with GHSV $=2592 \mathrm{~h}^{-1}$ and temperature $250{ }^{\circ} \mathrm{C}$ for the three differently reduced catalysts

\begin{tabular}{lccc}
\hline & 1.85 bar abs & 10.85 bar abs & 20.85 bar abs \\
\hline $\mathrm{CO}_{2}$ selectivity $(\%)$ & & \\
Reac-Syn & $16.20 \pm 1.92$ & $16.92 \pm 1.45$ & $20.58 \pm 1.68$ \\
Reac-H & $15.76 \pm 1.31$ & $17.15 \pm 3.13$ & $19.94 \pm 2.73$ \\
Reac-CO & $16.44 \pm 1.17$ & $23.58 \pm 2.14$ & $22.64 \pm 1.76$ \\
$\mathrm{CH}_{4}$ selectivity $(\%)$ & & \\
Reac-Syn & $15.60 \pm 2.86$ & $14.18 \pm 1.37$ & $13.33 \pm 0.62$ \\
Reac-H & $6.27 \pm 0.68$ & $14.05 \pm 3.50$ & $12.70 \pm 2.42$ \\
Reac-CO & $19.56 \pm 1.37$ & $19.78 \pm 3.68$ & $18.80 \pm 2.47$ \\
\hline
\end{tabular}

observed at shorter TOS and also what is reported in the literature. At reduced GHSV, the WGS reaction was enhanced for all three catalysts. The catalyst speciation that could be observed as the catalyst deactivated with TOS, resulted in the formation of magnetite, which is a

Table 7 Component selectivities at different pressures: (a) paraffin selectivity, (b) olefin selectivity, and (c) total (olefin + paraffin) and $\mathrm{C}_{5+}$ selectivity)

\begin{tabular}{|c|c|c|c|c|c|c|c|c|c|c|c|c|c|c|c|}
\hline \multirow{3}{*}{$\begin{array}{l}\text { (a) } \\
\text { Component } \\
\text { Reactor pressure } \\
\text { (bar) abs }\end{array}$} & \multicolumn{15}{|c|}{ Paraffin selectivity (\%) } \\
\hline & \multicolumn{4}{|l|}{$\mathrm{C}_{2} \mathrm{H}_{6}$} & \multicolumn{3}{|l|}{$\mathrm{C}_{3} \mathrm{H}_{8}$} & \multicolumn{4}{|c|}{$\mathrm{C}_{4} \mathrm{H}_{10}$} & \multicolumn{4}{|c|}{$\mathrm{C}_{5} \mathrm{H}_{12}$} \\
\hline & $\begin{array}{l}\text { Reac- } \\
\text { Syn }\end{array}$ & \multicolumn{2}{|c|}{$\begin{array}{l}\text { Reac- } \\
\mathrm{H}_{2}\end{array}$} & $\begin{array}{l}\text { Reac- } \\
\mathrm{CO}\end{array}$ & $\begin{array}{l}\text { Reac- } \\
\text { Syn }\end{array}$ & $\begin{array}{l}\text { Reac- } \\
\mathrm{H}_{2}\end{array}$ & $\begin{array}{l}\text { Reac- } \\
\mathrm{CO}\end{array}$ & \multicolumn{2}{|c|}{$\begin{array}{l}\text { Reac- } \\
\text { Syn }\end{array}$} & $\begin{array}{l}\text { Reac- } \\
\mathrm{H}_{2}\end{array}$ & $\begin{array}{l}\text { Reac- } \\
\mathrm{CO}\end{array}$ & $\begin{array}{l}\text { Reac- } \\
\text { Syn }\end{array}$ & \multicolumn{2}{|c|}{$\begin{array}{l}\text { Reac- } \\
\mathrm{H}_{2}\end{array}$} & Reac-CO \\
\hline 1.85 & 6.85 & 0.42 & \multicolumn{2}{|c|}{2.04} & 2.56 & 0.17 & 0.52 & \multicolumn{2}{|c|}{1.23} & 0.43 & 0.42 & 1.69 & \multicolumn{2}{|c|}{0.13} & 0.47 \\
\hline 10.85 & 6.77 & 2.39 & \multicolumn{2}{|c|}{3.11} & 3.09 & 0.15 & 1.32 & \multicolumn{2}{|c|}{1.99} & 2.30 & 0.99 & 2.65 & & 0.99 & 1.38 \\
\hline 20.85 & 6.97 & 2.66 & \multicolumn{2}{|c|}{3.94} & 4.21 & 0.40 & 2.83 & \multicolumn{2}{|c|}{2.39} & 2.94 & 1.55 & 3.54 & & 1.13 & 1.78 \\
\hline (b) & \multicolumn{15}{|c|}{ Olefin selectivity (\%) } \\
\hline Component & \multicolumn{4}{|l|}{$\mathrm{C}_{2} \mathrm{H}_{4}$} & \multicolumn{3}{|l|}{$\mathrm{C}_{3} \mathrm{H}_{6}$} & \multicolumn{4}{|c|}{$\mathrm{C}_{4} \mathrm{H}_{8}$} & $\mathrm{C}_{5} \mathrm{H}_{10}$ & & & \\
\hline $\begin{array}{l}\text { Reactor pressure } \\
\text { (bar) abs }\end{array}$ & $\begin{array}{l}\text { Reac- } \\
\text { Syn }\end{array}$ & $\begin{array}{l}\text { Reac } \\
\mathrm{H}_{2}\end{array}$ & $\begin{array}{l}\mathrm{Re} \\
\mathrm{CC}\end{array}$ & ac- & $\begin{array}{l}\text { Reac- } \\
\text { Syn }\end{array}$ & $\begin{array}{l}\text { Reac- } \\
\mathrm{H}_{2}\end{array}$ & $\begin{array}{l}\text { Reac- } \\
\mathrm{CO}\end{array}$ & $\begin{array}{l}\text { Reac } \\
\text { Syn }\end{array}$ & & $\begin{array}{l}\text { Reac- } \\
\mathrm{H}_{2}\end{array}$ & $\begin{array}{l}\text { Reac- } \\
\mathrm{CO}\end{array}$ & $\begin{array}{l}\text { Reac- } \\
\text { Syn }\end{array}$ & $\begin{array}{l}\mathrm{R} \\
\mathrm{H}\end{array}$ & $\begin{array}{l}\text { Reac- } \\
\mathrm{I}_{2}\end{array}$ & Reac-CO \\
\hline 1.85 & 4.98 & 2.75 & 5.8 & & 9.92 & 3.66 & 10.14 & 4.35 & & 2.73 & 6.53 & 2.99 & & .40 & 5.09 \\
\hline 10.85 & 2.85 & 2.59 & 1. & & 9.27 & 7.66 & 7.28 & 5.48 & & 4.63 & 4.41 & 3.91 & & 39 & 3.31 \\
\hline 20.85 & 1.24 & 1.76 & 0.6 & & 7.04 & 7.73 & 4.41 & 3.91 & & 4.28 & 2.37 & 2.64 & & .56 & 1.49 \\
\hline (c) & Overal & 11 hydroc & arbon s & electivit & ity (\%) & & & & & & & & & & \\
\hline Component & $\mathrm{C}_{2}$ & & & $\mathrm{C}_{3}$ & & & $\mathrm{C}_{4}$ & & & $\mathrm{C}_{5}$ & & & $\mathrm{C}_{5+}$ & & \\
\hline $\begin{array}{l}\text { Reactor pressure } \\
\text { (bar)abs }\end{array}$ & $\begin{array}{l}\text { Reac- } \\
\text { Syn }\end{array}$ & $\begin{array}{l}\text { Reac- } \\
\mathrm{H}_{2}\end{array}$ & $\begin{array}{l}\text { Reac- } \\
\text { CO }\end{array}$ & $\begin{array}{l}\text { Reac- } \\
\text { Syn }\end{array}$ & $\begin{array}{l}-\quad \text { Reac- } \\
\mathrm{H}_{2}\end{array}$ & $\begin{array}{l}\text { Reac- } \\
\text { CO }\end{array}$ & $\begin{array}{l}\text { Reac- } \\
\text { Syn }\end{array}$ & $\begin{array}{l}\text { Reac- } \\
\mathrm{H}_{2}\end{array}$ & $\begin{array}{l}\text { Reac- } \\
\text { CO }\end{array}$ & $\begin{array}{l}\text { - Reac- } \\
\text { Syn }\end{array}$ & $\begin{array}{l}\text { Reac- } \\
\mathrm{H}_{2}\end{array}$ & $\begin{array}{l}\text { Reac- } \\
\text { CO }\end{array}$ & $\begin{array}{l}\text { Reac- } \\
\text { Syn }\end{array}$ & $\begin{array}{l}\text { Reac- } \\
\mathrm{H}_{2}\end{array}$ & $\begin{array}{l}\text { Reac- } \\
\text { CO }\end{array}$ \\
\hline 1.85 & 11.83 & 3.17 & 7.90 & 12.48 & $8 \quad 3.82$ & 10.66 & 5.58 & 3.17 & 6.95 & 4.69 & 2.54 & 5.55 & 68.59 & 67.80 & 58.38 \\
\hline 10.85 & 9.63 & 4.98 & 4.54 & 12.36 & $\begin{array}{ll}6 & 8.81\end{array}$ & 8.59 & 7.48 & 6.93 & 5.41 & 6.56 & 4.39 & 4.68 & 60.84 & 48.07 & 59.20 \\
\hline 20.85 & 8.21 & 4.42 & 4.56 & 11.25 & $5 \quad 9.13$ & 7.25 & 6.30 & 7.22 & 3.92 & 6.18 & 4.69 & 3.28 & 70.64 & 46.53 & 59.17 \\
\hline
\end{tabular}

FTS results obtained for TOS 5000-10,000 at a GHSV of $2592 \mathrm{~h}^{-1}$ 
Fig. 9 The selectivity of $\mathrm{CO}_{2}$ and $\mathrm{CH}_{4}$ at different pressures, with GHSV $=2592 \mathrm{~h}^{-1}$ and temperature $250{ }^{\circ} \mathrm{C}$ for the three differently reduced catalyst
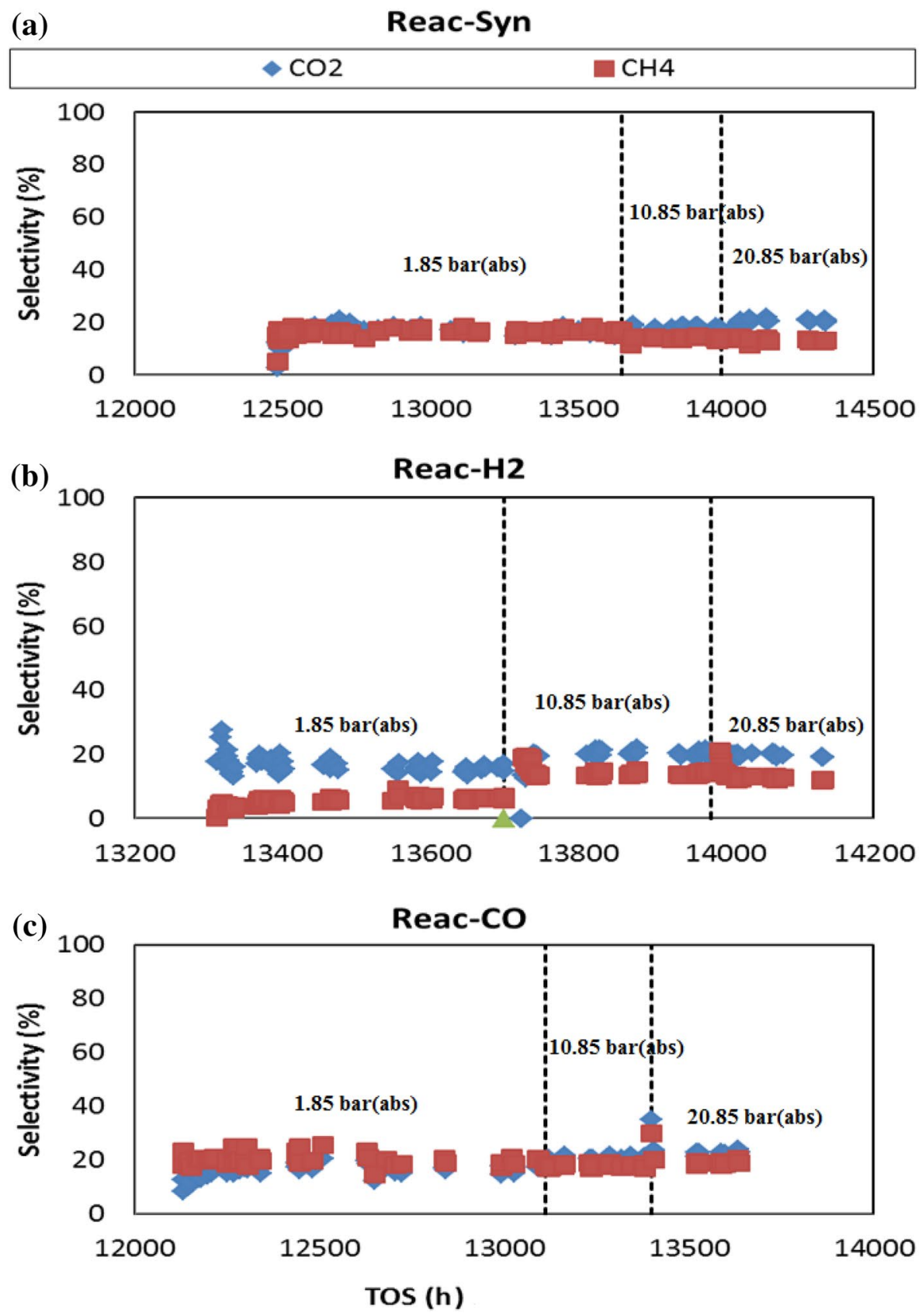

water gas shift (WGS) active catalyst. Catalyst characterization results suggest that deactivation was caused by oxidation of the catalyst and carbon deposition. It was found that olefin content decreased and paraffin increased with increased pressure; methane selectivity was essentially independent of reaction conditions.

These changes could have an impact on the design of a small-scale gas-to-liquid process designed to run at low pressure. The three differently reduced catalysts had similar optimum operating conditions. The optimum condition for paraffin production is high pressure and low GHSV [20.85 bar (abs): $648 \mathrm{~h}^{-1}$ ]. For olefins, it is low pressure and low GHSV [ 1.85 bar (abs): $648 \mathrm{~h}^{-1}$ ], while $\mathrm{C}_{5+}$ production is favored at high GHSV and is not affected by pressure. Extended operation was achieved quite easily and catalyst performance was stable during extended operation.

Acknowledgements The authors are grateful for financial support provided by the University of South Africa, National research foundation of South Africa and the Institute for the Development of Energy for African Sustainability (IDEAS) research unit at UNISA. 
Authors' contributions JG and AM did the laboratory work. DH and XL supervised the work. All the authors discused the results and the story line. JG wrote the first draft.

Open Access This article is distributed under the terms of the Creative Commons Attribution 4.0 International License (http://creativeco mmons.org/licenses/by/4.0/), which permits unrestricted use, distribution, and reproduction in any medium, provided you give appropriate credit to the original author(s) and the source, provide a link to the Creative Commons license, and indicate if changes were made.

\section{References}

1. Muleja AA, Yao Y, Glasser D, Hildebrandt D (2016) Effect of feeding nitrogen to a fixed bed Fischer-Tropsch reactor while keeping the partial pressures of reactants the same. Chem Eng J 293:151-160

2. Gorimbo J, Lu X, Liu X, Hildebrandt D, Glasser D (2017) A long term study of the gas phase of low pressure Fischer-Tropsch products when reducing an iron catalyst with three different reducing gases. Appl Catal A Gen 534:1-11

3. Chun DH, Park JC, Hong SY, Lim JT, Kim CS, Lee HT, Il Yang J, Hong S, Jung H (2014) Highly selective iron-based FischerTropsch catalysts activated by $\mathrm{CO}_{2}$-containing syngas. J Catal 317:135-143

4. Bukur DB, Lang X, Akgerman A, Feng Z (1997) Effect of Process Conditions on Olefin Selectivity during Conventional and Supercritical Fischer-Tropsch Synthesis. Ind Eng Chem Res 36:2580

5. Todic B, Nowicki L, Nikacevic N, Bukur DB (2016) FischerTropsch synthesis product selectivity over an industrial iron-based catalyst: effect of process conditions. Catal Today 261:28-39

6. Dictor RA, Bell AT (1986) Fischer-Tropsch synthesis over reduced and unreduced iron oxide catalysts. J Catal 97:121-136

7. Bukur DB, Nowicki L, Patel SA (1996) Activation studies with an iron Fischer-Tropsch catalyst in fixed bed and stirred tank slurry reactors. Can J Chem Eng 74:399-404

8. de Smit E, Weckhuysen BM (2008) The renaissance of iron-based Fischer-Tropsch synthesis: on the multifaceted catalyst deactivation behaviour. Chem Soc Rev 37:2758-2781
9. Tsakoumis NE, Voronov A, Rønning M, Van Beek W, Borg Ø, Rytter E, Holmen A (2012) Fischer-Tropsch synthesis : an XAS / XRPD combined in situ study from catalyst activation to deactivation. J Catal 291:138-148

10. Khodakov AY, Chu W, Fongarland P (2007) Advances in the development of novel cobalt Fischer-Tropsch Catalysts for synthesis of long-chain hydrocarbons and clean fuels advances in the development of novel cobalt Fischer-Tropsch catalysts for synthesis of long-chain hydrocarbons and clean fuel. Am Chem Soc 107:1692-1744

11. Mandal P, Chattopadhyay AP (2015) Excellent catalytic activity of magnetically recoverable $\mathrm{Fe}_{3} \mathrm{O}_{4}$-graphene oxide nanocomposites prepared by a simple method. Dalt Trans 44:11444-11456

12. Savost'yanov AP, Narochnyi GB, Yakovenko RE, Bakun VG, Zemlyakov ND (2014) Synthesis of high-molecular-weight hydrocarbons from $\mathrm{CO}$ and $\mathrm{H}_{2}$ over a cobalt catalyst. Catal Ind 6:292-297

13. Yan F, Qian W, Sun Q, Zhang H, Ying W, Fang D (2014) Product distributions and olefin-to-paraffin ratio over an iron-based catalyst for Fischer-Tropsch synthesis. React Kinet Mech Catal 113:471-485

14. Farias FEM, Sales FG, Fernandes FAN (2008) Effect of operating conditions and potassium content on Fischer-Tropsch liquid products produced by potassium-promoted iron catalysts. J Nat Gas Chem 17:175-178

15. Atashi H, Razmjooei S, Khorashadizadeh M, Shiva M, Tabrizi FF, Mousavi SAHS (2015) Effects of operating conditions on selectivity of $\mathrm{Fe}-\mathrm{Co}-\mathrm{Mn} / \mathrm{MgO}$ at high temperature $\mathrm{CO}$ hydrogenation. J Taiwan Inst Chem Eng 54:83-90

16. Huo C-F, Li Y-W, Jianguo W, Haijun J (2009) Insight into $\mathrm{CH}_{4}$ formation in iron-catalyzed Fischer-Tropsch synthesis. J Am Chem Soc 131:14713-14721

17. Pérez De Berti IO, Bengoa JF, Stewart SJ, Cagnoli MV, Pecchi G, Marchetti SG (2016) Effect of activation atmosphere in the Fischer-Tropsch Synthesis using a "quasi-model" catalyst of $\gamma-\mathrm{Fe}_{2} \mathrm{O}_{3}$ nanoparticles supported on SBA-15. J Catal 335:36-46

Publisher's Note Springer Nature remains neutral with regard to jurisdictional claims in published maps and institutional affiliations. 